\title{
HUBUNGAN TINGKAT KECEMASAN DENGAN PERUBAHAN DENYUT NADI PADA PASIEN EKSTRAKSI GIGI DI PUSKESMAS TUMINTING MANADO
}

\author{
${ }^{1}$ Beatrix I. Pontoh, \\ ${ }^{2}$ Damajanti H. C. Pangemanan, \\ ${ }^{3}$ Ni Wayan Mariati
}

\author{
${ }^{1}$ Kandidat Skripsi Program Studi Pendidikan Dokter Gigi Fakultas Kedokteran \\ Universitas Sam Ratulangi Manado \\ ${ }^{2}$ Program Studi Pendidikan Dokter Gigi Fakultas Kedokteran \\ Universitas Sam Ratulangi Manado \\ E-mail: beatrixignatiapontoh@yahoo.com
}

\begin{abstract}
Dental practice surely will always be accompanied by patient's anxiety. The anxiety itself is manifested through many ways. The physiological symptoms may occur, from the increasing pulse rate or excessive sweating. The objective of this research is to find out the relationship between the level of anxiety and the changes in the pulse rate of the patients who undergo tooth extraction. The methodological used in this study is descriptive and analytical from a cross sectional study performed in Puskesmas Tuminting Manado from 11 September to 1st October 2014. The population and sample were derived from the entire patients who visit Puskesmas Tuminting and undergo tooth extraction. The sample was drawn from the entire population according to specified inclusion criteria. The data was collected from questionnaires with Hamilton Anxiety Scale and the measurement of patient's pulse rate was performed during the waiting time and tooth extraction preparation. The data was computed by using SPSS Program version 20 and analyzed through univariate and bivariate Spearmen analysis. The result shows that patients who undergo tooth extraction were experiencing anxiety and the patients' pulse rate were increasing accordingly. The range of 31-40 years old were the highest age group who were experiencing anxiety and female experienced the highest level of anxiety. The relationship between anxiety and the changes in the pulse rate from the statistical study shows $\mathrm{p}$ value $=0.703$, hence $\mathrm{Ha}$ is rejected. Conclusion: is there is no relationship between level of anxiety and the changes of pulse rate on the patients who undergo tooth extraction in Puskesmas Tuminting, Manado.
\end{abstract}

Keywords: anxiety, pulse rate, tooth extraction

\begin{abstract}
Abstrak: Praktik Kedokteran Gigi tentunya tidak lepas dari kecemasan yang dialami oleh pasien. Kecemasan dapat bermanifestasi dalam berbagai cara. Tanda-tanda fisiologis yang dapat timbul, ditandai dengan meningginya denyut nadi atau berkeringat. Tujuan penelitian ini yaitu mengetahui hubungan tingkat kecemasan dengan perubahan denyut nadi pada pasien ekstraksi gigi di Puskesmas Tuminting Manado.Penelitian ini merupakan penelitian deskriptif analitik dengan pendekatan potong lintang (cross-sectional study) yang dilakukan di Puskesmas Tuminting Manado pada tanggal 11 September - 1 Oktober 2014. Populasi dan sampel ialah seluruh pasien yang berkunjung di Puskesmas Tuminting dan melakukan tindakan ekstraksi gigi yang berusia di atas 17 tahun serta sudah pernah melakukan ekstraksi gigi. Teknik pengambilan sampel menggunakan total populasi sesuai kriteria inklusi. Data diambil menggunakan kuesioner Hamilton Anxiety Scale dan pengukuran denyut nadi dilakukan saat menunggu dan saat berada di kursi dental sebelum tindakan ekstraksi gigi. Data diolah dengan menggunakan program SPSS versi 20 dan dianalisis menggunakan analisis
\end{abstract}


univariat dan bivariat menggunakan uji Spearmen.Hasil penelitian menunjukkan dalam tindakan ekstraksi gigi terdapat pasien yang mengalami kecemasan dan terdapat pasien yang mengalami peningkatan denyut nadi. Usia 31-40 tahun merupakan usia terbanyak yang mengalami kecemasan serta jenis kelamin perempuan paling banyak merasa cemas. Hubungan antara kecemasan ekstraksi gigi dengan perubahan denyut nadi dari hasil uji statistik diperoleh nilai $\mathrm{p}=0,703$ maka Ha ditolak. Simpulan: tidak terdapat hubungan antara tingkat kecemasan dengan perubahan denyut nadi pada pasien ekstraksi gigi di Puskesmas Tuminting Manado.

Kata kunci: kecemasan, denyut nadi, ekstraksi gigi

Kesehatan gigi dan mulut merupakan salah satu faktor yang melatarbelakangi status kesehatan masyarakat di tingkat nasional, provinsi, dan kabupaten/ kota. Berdasarkan laporan hasil Riset Kesehatan Dasar (RISKESDAS) Nasional tahun 2013, dari hasil wawancara sebesar $25,9 \%$ penduduk Indonesia mempunyai masalah gigi dan mulut dalam 12 bulan terakhir (potential demand). Di antara mereka, terdapat $31,1 \%$ yang menerima perawatan dan pengobatan dari tenaga medis gigi (perawat gigi, dokter gigi atau dokter gigi spesialis), sementara $68,9 \%$ lainnya tidak dilakukan perawatan. ${ }^{1}$

Salah satu tindakan perawatan dalam bidang Kedokteran Gigi yaitu ekstraksi gigi. Tindakan ekstraksi gigi ini disebabkan oleh tingkat pendidikan, ekonomi, sosial dan kesadaran dari masyarakat tentang pemeliharaan kesehatan gigi masih rendah, termasuk di Indonesia. Penderita umumnya datang ke dokter gigi jika telah timbul keluhan yang sangat mengganggu dengan kerusakan gigi sudah parah. ${ }^{2}$ Sebuah penelitian membuktikan bahwa orang yang sering mengalami kecemasan dalam ekstraksi gigi memiliki kondisi kesehatan gigi dan mulut yang lebih buruk dibandingkan mereka yang tidak mengalami gangguan kecemasan. ${ }^{3}$

Praktik Kedokteran Gigi tentunya tidak lepas dari kecemasan yang dialami oleh pasien. Penelitian yang dilakukan oleh Wardle menunjukkan bahwa tindakan ekstraksi gigi merupakan pencetus pertama kecemasan seseorang. ${ }^{4}$ Kecemasan pada tindakan ekstraksi gigi sering disebabkan oleh penggunaan benda-benda tajam seperti jarum, elevator (bein) dan tang, yang dimasukkan secara berurutan maupun bergantian dalam mulut. ${ }^{5}$ Selain itu kecemasan pasien biasanya berasal dari ketakutan terhadap rasa sakit. Adapun kecemasan dikarenakan mereka ragu terhadap apa yang akan mereka alami dan ada juga yang bersifat menurun dalam keluarga. ${ }^{6}$

Dilihat dari hasil penelitian yang telah dilakukan mengenai gambaran tingkat kecemasan pasien usia dewasa pra pencabutan gigi, kategori usia dan jenis kelamin seseorang turut mempengaruhi tingkat kecemasan dalam menghadapi ekstraksi gigi. Golongan usia dewasa muda dan perempuan merupakan pasien yang memiliki tingkat kecemasan tinggi. ${ }^{7}$ Angka prevalensi untuk gangguan cemas menyeluruh 3-8\% dan rasio antara perempuan dan laki-laki sekitar 2:1. ${ }^{8}$

Kecemasan dapat bermanifestasi dalam berbagai cara. Masing-masing orang menunjukkan dan mengalami kecemasan dalam cara yang berbeda. Tanda-tanda fisiologis yang dapat timbul, ditandai dengan meningginya denyut nadi atau berkeringat. $^{6}$ Kecemasan inilah yang membuat masyarakat tetap bertahan dengan masalah gigi dan mulut yang ada sampai pada akhirnya gigi tersebut sudah tidak bisa dipertahankan lagi dan harus mengalami kecemasan yang lebih parah karena harus menerima tindakan ekstraksi gigi. Untuk itu perlu adanya peran serta dokter gigi, perawat gigi dan mahasiwa kedokteran gigi serta dinas terkait untuk dapat saling mengusahakan kegiatan promotif dan preventif di masyarakat dalam memberikan informasi mengenai pentingnya menjaga dan memelihara kesehatan gigi dan mulut.

\section{BAHAN DAN METODE PENELITIAN}

Penelitian ini merupakan penelitian deskriptif analitik dengan menggunakan pendekatan potong lintang (cross-sectional 
study). Jumlah sampel yang diteliti tahun, dengan teknik pengambilan sampel menggunakan total populasi. Pasien diberikan kuesioner untuk dijawab dan diukur tingkat kecemasan berdasarkan Hamilton Anxiety Scale. Selanjutnya pasien dilakukan pengukuran denyut nadi. Pengukuran denyut nadi dilakukan ulang pada saat berada di dental unit sebelum dilakukan tindakan ekstraksi gigi. Setelah memperoleh semua data yang diperlukan, data diolah dan disajikan berdasarkan distribusi frekuensi dalam bentuk tabel.

\section{HASIL PENELITIAN}

Tabel 1. Distribusi frekuensi berdasarkan tingkat kecemasan sebelum dilakukan ekstraksi gigi

\begin{tabular}{ccc}
\hline Tingkat Kecemasan & $\mathrm{n}$ & $\%$ \\
\hline Tidak cemas & 21 & 67,7 \\
Ringan & 7 & 22,6 \\
Sedang & 3 & 9,3 \\
Berat & 0 & 0 \\
Total & 31 & 100 \\
\hline
\end{tabular}

Tabel 2. Distribusi frekuensi berdasarkan perubahan denyut nadi saat menunggu dan saat berada di kursi dental

\begin{tabular}{ccc}
\hline $\begin{array}{c}\text { Perubahan } \\
\text { denyut nadi }\end{array}$ & $\mathrm{n}$ & $\%$ \\
\hline Tetap & 1 & 3,2 \\
Naik & 25 & 80,6 \\
Turun & 5 & 16,1 \\
Total & 31 & 100 \\
\hline
\end{tabular}

Tabel 3. Distribusi frekuensi kecemasan berdasarkan kelompok usia

\begin{tabular}{ccccccccc}
\hline \multirow{2}{*}{$\begin{array}{c}\text { Usia } \\
\text { (Tahun) }\end{array}$} & \multicolumn{7}{c}{$\begin{array}{c}\text { Tidak } \\
\text { cemas }\end{array}$} & \multicolumn{2}{c}{ Ringan } & \multicolumn{2}{c}{ Sedang } & \multicolumn{2}{c}{ Berat } \\
& $\mathrm{n}$ & $\%$ & $\mathrm{n}$ & $\%$ & $\mathrm{n}$ & $\%$ & $\mathrm{n}$ & $\%$ \\
\hline $17-20$ & 0 & 0 & 1 & 3,2 & 0 & 0 & 0 & 0 \\
$21-30$ & 1 & 3,2 & 0 & 0 & 2 & 6,5 & 0 & 0 \\
$31-40$ & 3 & 9,7 & 3 & 9,7 & 1 & 3,2 & 0 & 0 \\
$41-50$ & 11 & 35,5 & 1 & 3,2 & 0 & 0 & 0 & 0 \\
$51-60$ & 4 & 12,9 & 0 & 0 & 0 & 0 & 0 & 0 \\
$61-70$ & 2 & 6,5 & 1 & 3,2 & 0 & 0 & 0 & 0 \\
$71-80$ & 0 & 0 & 1 & 3,2 & 0 & 0 & 0 & 0 \\
\hline
\end{tabular}

sebanyak 31 orang yang berusia di atas 17

Tabel 4. Distribusi frekuensi kecemasan berdasarkan jenis kelamin

\begin{tabular}{ccccc}
\hline Tingkat & \multicolumn{2}{c}{ Laki-laki } & \multicolumn{2}{c}{ Perempuan } \\
kecemasan & $\mathrm{n}$ & $\%$ & $\mathrm{n}$ & $\%$ \\
\hline Tidak cemas & 6 & 19,4 & 15 & 48,4 \\
Ringan & 3 & 9,7 & 4 & 12,9 \\
Sedang & 1 & 3,2 & 2 & 6,5 \\
Berat & 0 & 0 & 0 & 0 \\
Total & 10 & 32,3 & 21 & 67,7 \\
\hline
\end{tabular}

\section{BAHASAN}

Denyut nadi distimulasi oleh serabut saraf simpatis dan penurunan frekuensi denyut nadi distimulasi oleh serabut parasimpatis. ${ }^{11}$ Denyut nadi merupakan bagian dari sistem kerja jantung, sehingga pada keadaan jantung yang berdebar-debar dalam teori yang dikemukakan oleh para ahli psikologis merupakan salah satu wujud gejala fisik pada kecemasan tingkat fisiologis. ${ }^{12}$ Dari penelitian yang dilakukan, peneliti menyimpulkan bahwa terjadinya peningkatan denyut nadi dikarenakan ada ketakutan dalam diri pasien dengan jarum suntik dan peralatan dokter gigi lainnya serta resiko yang akan terjadi saat ekstraksi gigi berlangsung.

Penelitian tingkat kecemasan dari hasil distribusi frekuensi kecemasan berdasarkan kelompok usia, peneliti mendapati jumlah pasien yang mengalami kecemasan terbanyak berada di usia 31-40 tahun dengan jumlah 4 orang (12,9\%) dan diikuti kelompok usia 21-30 tahun berjumlah 2 orang $(6,5 \%)$. Hasil penelitian ini hampir sama dengan hasil penelitian yang dilakukan oleh Kumar dkk yaitu menjelaskan bahwa tingkat kecemasan dental yang paling tinggi berada pada usia 25-34 tahun. ${ }^{13}$ Menurut peneliti, ada banyak alasan pasien merasa cemas, salah satunya pengalaman trauma dental masa lalu yang masih membekas dalam diri yang tidak dapat dilupakan oleh pasien. 
Pontoh, Pangemanan, Mariati: Hubungan tingkat kecemasan...

Tabel 5. Hubungan antara kecemasan ekstraksi gigi dengan perubahan denyut nadi

\begin{tabular}{|c|c|c|c|c|c|c|c|c|c|}
\hline & \multicolumn{8}{|c|}{ Perubahan denyut nadi } & \multirow{3}{*}{$P$ value } \\
\hline & \multicolumn{2}{|c|}{ Teta } & \multicolumn{2}{|c|}{ Naik } & \multicolumn{2}{|c|}{ Turun } & \multicolumn{2}{|c|}{ Total } & \\
\hline & $\mathrm{n}$ & $\%$ & $\mathrm{n}$ & $\%$ & $\mathrm{n}$ & $\%$ & $\mathrm{n}$ & $\%$ & \\
\hline Tidak cemas & 1 & 3,2 & 16 & 51,6 & 4 & 12,9 & 21 & 67,7 & \\
\hline Ringan & 0 & 0 & 6 & 19,4 & 1 & 3,2 & 7 & 22,6 & \\
\hline Sedang & 0 & 0 & 3 & 9,7 & 0 & 0 & 3 & 9,7 & 0,703 \\
\hline Berat & 0 & 0 & 0 & 0 & 0 & 0 & 0 & 0 & \\
\hline Total & 1 & 3,2 & 25 & 80,6 & 5 & 16,1 & 3 & 100 & \\
\hline
\end{tabular}

Keadaan cemas pada saat ekstraksi gigi bisa dialami oleh siapa saja. Hasil distribusi frekuensi kecemasan berdasarkan jenis kelamin menunjukkan perempuan lebih banyak mengalami kecemasan untuk melakukan ekstraksi gigi meskipun semua pasien yang diteliti sudah pernah melakukan prosedur pencabutan gigi beberapa kali. Hal ini dikarenakan jumlah pasien perempuan lebih dominan dibandingkan laki-laki yang relatif sedikit. Dari 31 pasien ekstraksi gigi, laki-laki yang mengalami kecemasan berjumlah 4 orang $(12,9 \%)$ dan perempuan 6 orang $(19,4 \%)$. Penelitian ini sesuai dengan penelitian yang dilakukan sebelumnya oleh para ahli di Australia yang mengatakan perempuan lebih banyak mengalami kecemasan dibandingkan laki-laki. ${ }^{10}$ Berdasarkan pengamatan peneliti, hal ini disebabkan karena perempuan cenderung lebih sensitif perasaannya dibanding dengan laki-laki yang memiliki jiwa pemberani.

Pada Tabel 5, hubungan antara kecemasan ekstraksi gigi dengan perubahan denyut nadi dari hasil uji statistik diperoleh nilai $\mathrm{p}=0,703$, karena nilai $\mathrm{p}(0,703)>\alpha$ $(0,05)$, maka Ha ditolak ( $\mathrm{p}$ value $>\alpha$ ). Uji statistik menunjukkan tidak terdapat hubungan yang signifikan. Artinya, hubungan tingkat kecemasan dengan perubahan denyut nadi pada pasien ekstraksi gigi tidak bermakna.

Ada beberapa alasan mengapa penelitian ini tidak menunjukkan hubungan yang signifikan. Pertama, dikarenakan pasien yang diteliti merupakan pasien yang sudah pernah mengalami tindakan ekstraksi gigi sehingga pasien sudah bisa mengontrol rasa cemas dalam diri mereka. Kedua, jumlah pasien yang diteliti relatif sedikit, yaitu hanya berjumlah 31 orang sehingga terdapat keterbatasan dalam menetukan hubungan antara tingkat kecemasan dengan perubahan denyut nadi pasien ekstraksi gigi.

\section{SIMPULAN}

1. Pasien yang memenuhi kriteria untuk dijadikan sampel penelitian berjumlah 31 orang. Hasil yang diperoleh menunjukkan jumlah pasien yang mengalami kecemasan ringan dan sedang yaitu 10 orang.

2. Pasien ekstraksi gigi yang mengalami perubahan denyut nadi saat menunggu dan saat berada di kursi dental sebelum menerima tindakan ekstraksi gigi berjumlah 30 orang.

3. Tidak terdapat hubungan antara tingkat kecemasan dengan perubahan denyut nadi pada pasien ekstraksi gigi di Puskesmas Tuminting Manado.

\section{SARAN}

1. Dokter gigi perlu memahami cara mengatasi kecemasan pasien agar dalam penanganannya, seorang dokter gigi dapat menenangkan pasien dari merasa cemas menjadi tidak cemas. Masih banyak dokter gigi yang hanya terfokus pada faktor fisik dan tidak memperhatikan faktor psikis pasien.

2. Usaha promosi tentang kesehatan gigi dan mulut kepada masyarakat perlu ditingkatkan agar masyarakat yang cenderung takut ke dokter gigi lebih mengenal tentang kesehatan gigi dan mulut yang sebenarnya tidak 
menakutkan seperti yang dipandang mereka.

\section{DAFTAR PUSTAKA}

1. RISKESDAS. Badan Penelitian dan Pengembangan Kesehatan Kementerian RI. Jakarta 2013. p. 146-7.

2. Riawan L. Teknik dan Trik Pencabutan Gigi dengan Penyulit. Prosiding Temu Ilmiah Bandung Dentistry 6 Persatuan Dokter Gigi Indonesia (PDGI) Cabang Kota Bandung. Bandung. 2009. p. 2

3. Jason M. How Do We Measure Dental Fear and What are We Measuring? Oral Health Prev Dent 2010;8: 107-115

4. Setiawan AS, Zidnia H, Sasmita IS. Mozart effect on dental anxiety in 6-12 year old children. Dent J. 2010;43(1):17-20.

5. Mansjoer A, editor. Kapita selekta kedokteran Jilid 1 (Edisi Ketiga). Jakarta: Media Aesculapius, 2001;p.178-85.

6. Pusparatri RA. Kecemasan dan Penyebabnya serta Cara Mengatasinya. [online] 10 Juli 2013. Diakses dari: http://www.seputargigi.com/component /content/article/34-artikel/112-

kecemasan-dan-penyebabnya-sertacara-mengatasinya.html

7. Mawa MAC. Gambaran tingkat kecemasan pasien usia dewasa pra tindakan pencabutan gigi di Balai Pengobatan Rumah Sakit Gigi dan Mulut Manado. e-Gigi Journal. 2013;1(2):p. 5,7

8. Elvira SD, Hadisukanto G, editor. Buku Ajar Psikiatri. Jakarta: Badan Penerbit FKUI.2010. p. 230

9. Tangkere H. Gambaran Kecemasan Pasien Saat Menjalani Prosedur Ekstraksi Gigi Sambil Mendengarkan Musik Mozart Di Puskesmas.e-Gigi Journal. 2013;1(1):p. 74-5

10. Hmud R, Walsh LJ. Dental Anxiety: Causes, Complications and Management Approaches. J Minim Interv Dent 2009; 2(1): 70

11. Prince SA, Wilson LM. Patofisiologi Konsep Klinis Proses-Proses Penyakit. Ed 6. Jakarta: Penerbit Buku Kedokteran EGC. 2000. P. 480-92.

12. Mu'arifah A. Hubungan Kecemasan dan Agresivitas. Indonesian Psychological Journal. Agustus 2005; 2 (2):105

13. Kumar S, Bhargav $P$, Patel A, Bhati $M$, Balasubramanyam G, Duraiswamy P, et al. Does dental anxiety influences oral health-related quality of life ? Observation from a cross-sectional study among adults in Udaipur district, India. Journal of Oral Science 2009 ; $51(2): 245-254$. 